\title{
Ineficiência do silício no controle da ferrugem do cafeeiro em solução nutritiva
}

\author{
Vivian Carré-Missio ${ }^{1}$, Fabrício Á. Rodrigues ${ }^{1}$, Daniel A. Schurt ${ }^{1}$, Sandra C. Pereira ${ }^{2}$, Maria Goreti A. \\ Oliveira $^{2}$ \& Laércio Zambolim ${ }^{1}$
}

${ }^{1}$ Departamento de Fitopatologia; ${ }^{2}$ Departamento de Bioquímica Agrícola, Universidade Federal de Viçosa, 36570-000, Viçosa, MG, Brasil

Autor para correspondência: Fabrício Á. Rodrigues, e-mail: fabricio@ufv.br

\begin{abstract}
RESUMO
A ferrugem, causada por Hemileia vastatrix, é a principal doença do cafeeiro. Este trabalho avaliou o efeito do silício ( $\mathrm{Si}$ ) em alguns componentes de resistência do cafeeiro à ferrugem e o possível aumento na atividade de quitinases (QUI), $\beta$-1,3-glucanases (GLU) e peroxidases (POX). Mudas de cafeeiro (cv. Catuaí vermelho 44) foram crescidas em solução nutritiva de Clarck modificada, aerada, contendo $0(-\mathrm{Si})$ ou $2 \mathrm{mmol} \mathrm{L}^{-1} \mathrm{Si}(+\mathrm{Si})$ por 45 dias e inoculadas com $H$. vastatrix. Não houve diferença significativa entre os tratamentos -Si e $+\mathrm{Si}$ para o teor foliar de $\mathrm{Si}$, mas o teor desse elemento nas raízes foi significativamente maior para o tratamento +Si. Os tratamentos -Si e +Si não foram estatisticamente diferentes para o período de incubação, período latente, número de pústulas por folha, área pustular, expansão de pústulas e área abaixo da curva do progresso da ferrugem. A atividade de QUI, GLU e POX aumentou após a inoculação com $H$. vastatrix, embora com aumentos e decréscimos durante as épocas de coletas. O Si não teve efeito pronunciado em maximizar a atividade dessas enzimas, salvo incrementos em épocas de coletas específicas. Os resultados deste estudo indicaram que o cafeeiro foi ineficiente em translocar o Si das raízes para a parte aérea, restringindo-o exclusivamente ao sistema radicular o que não garantiu o aumento da resistência do cafeeiro à ferrugem
\end{abstract}

Palavras-chave: Hemileia vastatrix, componentes de resistência, enzimas de defesa.

\begin{abstract}
Inefficiency of silicon in leaf rust control on coffee grown in nutrient solution

Coffee leaf rust, caused by Hemileia vastatrix, is the most important disease on coffee. This study aimed to evaluate the effect of silicon ( $\mathrm{Si}$ ) on some components of coffee resistance to rust and to determine if it could increase the activity of chitinases (CHI), $\beta$ 1,3-glucanases (GLU), and peroxidases (POX). Coffee plants (cultivar "Catuaí vermelho 44") were grown on aerated Clarck's nutrient solution containing $0(-\mathrm{Si})$ or $2 \mathrm{mmol} \mathrm{L}^{-1} \mathrm{Si}(+\mathrm{Si})$ for 45 days and inoculated with $H$. vastatrix. There was no significant difference between the $-\mathrm{Si}$ and $+\mathrm{Si}$ treatments for $\mathrm{Si}$ content in leaf tissue, but $\mathrm{Si}$ content in root tissue was significantly higher for the $+\mathrm{Si}$ treatment. The $-\mathrm{Si}$ and + Si treatments were not significantly different for incubation period, latent period, number of pustules per leaf, pustule size, pustule expansion, and area under rust progress curve. The activity of CHI, GLU, and POX increased after inoculation with $H$. vastatrix, even with increase or decrease in activities during the sampling times. There was not a pronounced effect of Si in increasing the activity of these enzymes, except for rare increases in specific sampling times. Results from this study indicated that coffee plants were inefficient in uptaking Si from the nutrient solution and translocating it to the shoot. Silicon was exclusively restricted to the root system, which did not guarantee an increase in coffee resistance to rust.
\end{abstract}

Keywords: Hemileia vastatrix, components of host resistance, defense enzymes.

O cultivo do cafeeiro (Coffea arabica L.) é um desafio aos produtores devido ao grande número de doenças e pragas que acometem essa cultura. A ferrugem, causada pelo fungo Hemileia vastatrix Berkeley \& Broome, constitui-se a principal doença do cafeeiro, atingindo quase todas as regiões produtoras no Brasil e pode causar perdas de até 50\% na produção (Zambolim et al., 2002). O manejo

Parte da Tese de Doutorado da primeira autora. Universidade Federal de Viçosa. Viçosa MG. 2008. da ferrugem envolve principalmente o uso de fungicidas protetores cúpricos, sistêmicos do grupo dos triazóis, isoladamente ou em mistura com as estrobilurinas, e o uso de cultivares resistentes (Zambolim et al., 2002).

Os nutrientes atuam das mais variadas formas possíveis na resposta das plantas ao ataque por patógenos. Muitos nutrientes são cofatores enzimáticos, ativadores, inibidores ou moduladores de vários processos metabólicos na planta, bem como podem participar na síntese de compostos utilizados em barreiras físicas e ou químicas. Assim, a nutrição mineral das plantas determina em grande 
parte a resistência ou a susceptibilidade delas às diversas doenças (Marschner, 1995). O alto teor de silício (Si) nos tecidos de algumas espécies de plantas, principalmente monocotiledôneas (Mitani \& Ma, 2005), tem contribuído para aumentar a resistência a pragas, doenças, bem como a diversos tipos de estresses abióticos tais como altas temperaturas, déficit hídrico e toxidez de ferro e manganês às raízes (Datnoff et al., 2007).

Os mecanismos pelos quais o $\mathrm{Si}$ atua na resistência das plantas à patógenos ainda não estão totalmente esclarecidos. A hipótese da formação de uma barreira física abaixo da cutícula após a polimerização do ácido monosilícico explica, em parte, o aumento da resistência do arroz a brusone (Datnoff et al., 2007). Tentativamente, essa hipótese vem sendo usada por vários pesquisadores como um dos argumentos para explicar a resistência de algumas espécies de plantas a certos patógenos quando essas são supridas com Si. Contudo, o abundante acúmulo de compostos fenólicos associados com as estruturas de certos patógenos nos sítios de infecção, os aumentos na produção de fitoalexinas em arroz, na transcrição de alguns genes em arroz associados com a resistência à brusone (Rodrigues et al., 2005; Datnoff et al., 2007), e na atividade de enzimas líticas à parede celular fúngica ou associadas com o metabolismo secundário da planta (Liang et al., 2005) reforçam a hipótese de que o Si potencializa mecanismos de defesa em plantas e não atua apenas de forma passiva na resistência. Em cafeeiro, sabe-se que plantas crescendo em solo contendo Si foram mais resistentes à cercosporiose, resistência essa atribuída à deposição de Si na superfície foliar e uma camada de cera e cutícula mais espessas (Pozza et al., 2004). O presente trabalho avaliou o efeito do Si em alguns componentes de resistência do cafeeiro à ferrugem e na atividade de algumas enzimas comumente associadas com a defesa das plantas a patógenos.

Mudas de cafeeiro (cv. Catuaí vermelho 44) no estádio de orelha de onça, obtidas de sementes germinadas em leito de areia umedecido, foram transplantadas para vasos plásticos contendo $3,5 \mathrm{~L}$ de solução nutritiva de Clarck (1975) com algumas modificações. Essa solução nutritiva foi composta, em mmol L-1, de 5,7 de $\mathrm{N}_{-} \mathrm{NO}_{3}$ ; 1 de $\mathrm{N}_{-\mathrm{NH}_{4}^{+}}^{+} ; 0,1$ de $\mathrm{P}-\mathrm{H}_{2} \mathrm{PO}_{4}^{-} ; 2,4$ de $\mathrm{K} ; 1,2$ de $\mathrm{Ca}^{2+}$; 0,6 de $\mathrm{Mg}^{++} ; 0,7$ de $\mathrm{S}_{-\mathrm{SO}_{4}}^{--}$; e, em $\mu$ mol L-1, 35 de $\mathrm{Fe}$; 0,8 de $\mathrm{Cu} ; 1,5$ de $\mathrm{Zn} ; 5$ de $\mathrm{Mn} ; 17$ de B, e 0,1 de Mo. A solução nutritiva, aerada, foi trocada a cada sete dias e o $\mathrm{pH}$ monitorado a cada dois dias e mantido próximo a 5,5 com adição de soluções $1 \mathrm{M}$ de $\mathrm{HCl}$ ou $\mathrm{NaOH}$. As doses de $\mathrm{Si}$ utilizadas na solução nutritiva foram 0 e $2 \mathrm{mmol} \mathrm{L}^{-1} \mathrm{Si}$. O Si foi fornecido às plantas na forma de ácido monosilícico, o qual foi obtido pela passagem de uma solução de silicato de potássio (Fertisil ${ }^{\circledR}$, PQ Silicas Brasil Ltda) através de uma coluna de troca catiônica (Ma et al., 2002).

Plantas de café (cv. Catuaí vermelho 44) na área experimental do Viveiro de Café do Departamento de Fitopatologia da Universidade Federal de Viçosa foram usadas para a obtenção de uredósporos de $H$. vastatrix. Os uredósporos foram recolhidos das pústulas com auxílio de um pincel e mantidos em ampolas de vidro dentro de um dessecador em geladeira. A viabilidade dos uredósporos foi avaliada antes da inoculação das mudas. Para tal, uma alíquota de $50 \mu \mathrm{L}$ de uma suspensão de uredósporos $(1 \mathrm{mg} /$ $\mathrm{mL}$ ) foi colocada em cinco placas de Petri contendo ágarágua a $2 \%$. Em seguida, as placas foram mantidas a $22^{\circ} \mathrm{C}$ no escuro, determinando-se o percentual de uredósporos germinados, sob microscópio de luz, às $16 \mathrm{~h}$ após o início do teste, sendo que a germinação desses foi paralisada com lactofenol. Os uredósporos utilizados no preparo da suspensão tiveram germinação de $35 \%$. A face abaxial do $2^{\circ}$ par de folhas, a partir do ápice, de mudas com três pares de folhas crescidas em solução nutritiva com ou sem a presença de Si por 45 dias foi inoculada com uma suspensão de uredósporos $(1 \mathrm{mg} / \mathrm{mL})$ de $H$. vastatrix, utilizandose um atomizador Paasche (modelo VL-SET) alimentado por sucção. Em seguida, as mudas foram transferidas para câmara úmida (UR $95 \pm 5 \%, 25^{\circ} \mathrm{C}$ ) e mantidas no escuro por $48 \mathrm{~h}$. Após esse período, as mudas foram transferidas para câmara de crescimento a $22^{\circ} \mathrm{C}$ com fotoperíodo de $12 \mathrm{~h}$ sob luz fluorescente para a expressão dos sintomas da ferrugem.

Foram avaliados os seguintes componentes de resistência nas folhas inoculadas de cada planta: período de incubação (PI) - observação visual diária a partir do $10^{\circ}$ dia da inoculação até a constatação dos primeiros sintomas ("flecks") de ferrugem; período latente $\left(\mathrm{PL}_{60}\right)$ - avaliado visualmente até o aparecimento de uredósporos em seis de um total de 10 pústulas selecionadas, ao acaso, em cada uma das folhas inoculadas; expansão de pústulas: 10 pústulas foram selecionadas, ao acaso, nas duas folhas de cada muda e seus comprimentos foram obtidos com paquímetro digital. As medições foram realizadas após a ocorrência do $\mathrm{PL}_{60} \mathrm{e}$ depois a cada dois dias; área pustular $\left(\mathrm{mm}^{2}\right)$ - foi medido o diâmetro maior e menor de cada uma das 10 pústulas selecionadas para avaliar a expansão de pústulas; número total de pústulas por folha (NTPF); severidade da ferrugem - avaliada a cada cinco dias após a ocorrência do PI com auxílio de uma escala desenvolvida por Kushalappa (1978), totalizando cinco avaliações. Os dados da severidade foram utilizados para calcular a área abaixo da curva do progresso da ferrugem (AACPF).

O progresso da ferrugem foi avaliado utilizando-se uma escala com notas variando de 1 a 8 sendo: 1 - ausência de sintomas; 2 - "flecks" em pequenas áreas cloróticas de difícil observação macroscópica, mas visíveis com lupa de bolso ou quando observada contra a luz; 3 - "flecks" em pequenas áreas cloróticas; 4 - pústulas de tamanho médio a grande com halo clorótico, mas sem esporulação; 5 pústulas de tamanho médio a grande com halo clorótico contendo uredósporos; 6 - pústulas com halo clorótico e pouca esporulação; 7 - pústulas com halo clorótico e com esporulação intermediária e 8 - pústulas com halo clorótico e com esporulação intensa.

Após a finalização do experimento, as mudas foram divididas em folhas, caule e raiz determinando- 
se as variáveis: diâmetro do caule, altura da parte aérea, comprimento do sistema radicular e peso da matéria seca de folhas, caule e raiz. O diâmetro do caule foi medido a 2 $\mathrm{cm}$ acima da região do sistema radicular com paquímetro digital. Considerou-se como altura da parte aérea, a região compreendida entre a gema apical até o início do sistema radicular. Para o comprimento do sistema radicular, considerou-se a região compreendida entre o início do sistema radicular até a extremidade máxima da raiz. Para a determinação do peso da matéria seca de folhas, caule e raiz, esses materiais vegetais foram armazenados separadamente em sacos de papel e colocados em estufa com circulação forçada de ar a $65^{\circ} \mathrm{C}$ por $72 \mathrm{~h}$. No final do experimento, amostras de folhas e raízes, obtidas das mudas das repetições de cada tratamento, foram lavadas com água deionizada, secadas em estufa com ventilação forçada de ar a $60^{\circ} \mathrm{C}$ por $72 \mathrm{~h}$ e trituradas em moinho tipo Wiley com peneira de 20 mesh para determinação do teor de $\mathrm{Si}$ (Datnoff et al., 2007).

Um experimento independente foi conduzido para obtenção de folhas para as determinações enzimáticas. Dois pares de folhas de mudas de cafeeiro, crescidas em solução nutritiva com ou sem a presença de Si por 45 dias, foram inoculados com $H$. vastatrix. As folhas inoculadas foram coletadas aos 5, 10, 15, 20 e 30 dias após inoculação (DAI). Essas datas de coleta foram definidas com base no PI, $\mathrm{PL}_{60}$ e progresso da ferrugem nas condições experimentais do presente estudo. Cada amostra coletada foi composta por quatro folhas obtidas de cada muda para cada uma das enzimas nos dois tratamentos (presença e ausência de Si na solução nutritiva). Três mudas foram utilizadas em cada época de coleta. As amostras de folhas foram colocadas individualmente em pacotes de papel alumínio, congeladas em nitrogênio $\left(\mathrm{N}_{2}\right)$ líquido e armazenadas em ultrafreezer a $-80^{\circ} \mathrm{C}$ até análise.

Para a determinação da atividade de quitinases (EC 3.2.1.14) e $\beta$-1,3-glucanases (EC 3.2.1.14), amostras de folhas pesadas e congeladas em $\mathrm{N}_{2}$ líquido foram trituradas em almofariz com adição de polivinilpolipirrolidona (PVPP) $1 \%(\mathrm{p} / \mathrm{v})$. O pó obtido foi macerado em tampão fosfato de sódio $50 \mathrm{mM}, \mathrm{pH}$ 6,5, contendo fluoreto de fenilmetilsulfonila (PMSF) $1 \mathrm{mM}$. A centrifugação foi feita a $20.000 \mathrm{x} g$ por $25 \mathrm{~min}$ a $4^{\circ} \mathrm{C}$. Uma alíquota do sobrenadante foi utilizada para determinação da concentração de proteínas (Silva et al., 2001). A atividade de quitinases foi determinada conforme método descrito por Harman et al. (1993) e Roberts \& Selitrennikoff (1988). As amostras tiveram a absorbância registrada no comprimento de onda 410 nm em um ensaio colorimétrico no espectrofotômetro. Todas as incubações foram realizadas em triplicatas. Subtraiu-se o valor de absorbância de cada amostra do valor de absorbância do controle (uma mistura idêntica à da amostra, com a reação paralisada no início). Utilizou-se para os cálculos o coeficiente de extinção molar 7 x $10^{3} \mathrm{mM}$ ${ }^{1} . \mathrm{cm}^{-1}$ (Yedidia et al., 1999) e os resultados foram expressos em M.min ${ }^{-1} / \mathrm{mg}$ de proteína.
A atividade de $\beta$-1,3-glucanases foi determinada conforme método descrito por Lever (1972). Uma alíquota do sobrenadante foi utilizada para determinação da concentração de proteínas (Silva et al., 2001). As amostras tiveram a absorbância registrada no comprimento de onda $540 \mathrm{~nm}$ em um ensaio colorimétrico no espectrofotômetro. Todas as incubações foram realizadas em triplicatas. Subtraiu-se o valor de absorbância de cada amostra do valor de absorbância do controle (uma mistura idêntica à da amostra, com a reação paralisada no início). Os resultados foram expressos em unidades de absorbância. $\mathrm{min}^{-1} / \mathrm{mg}$ de proteína.

Para determinação da atividade de peroxidases (EC 1.11.1.7), amostras pesadas e congeladas em $\mathrm{N}_{2}$ líquido foram trituradas no almofariz com adição de PVPP $1 \%$ (p/v). O pó obtido foi macerado em tampão fosfato de potássio 100 mM, pH 6,8, contendo PMSF 1mM e ácido etilenodiamino tetra-acético (EDTA) $0,1 \mathrm{mM}$. A centrifugação foi feita a $12.000 \mathrm{x} g$ por $15 \mathrm{~min}$ a $4^{\circ} \mathrm{C}$. Uma alíquota do sobrenadante foi utilizada para determinação da concentração de proteínas (Silva et al., 2001). A atividade de peroxidases foi determinada conforme método descrito por Kar \& Mishra (1976). O aumento na absorbância foi registrado no comprimento de onda $420 \mathrm{~nm}$ em um ensaio colorimétrico no espectrofotômetro durante um período de $5 \mathrm{~min}$. Todas as incubações foram realizadas em triplicatas. Utilizou-se para os cálculos o coeficiente de extinção molar $2,47 \mathrm{mM}$ ${ }^{1} . \mathrm{cm}^{-1}$ (Chance \& Maehley, 1955) e os resultados foram expressos em M.min ${ }^{-1} / \mathrm{mg}$ de proteína. Os experimentos foram instalados em delineamento inteiramente casualizado com dez repetições. Cada repetição foi constituída por um vaso plástico contendo quatro mudas de cafeeiro. Os experimentos foram repetidos e os dados de cada variável foram combinados após confirmado a homogeneidade de variância pelo teste de Bartlett. Os dados foram submetidos à análise de variância e as médias dos tratamentos comparadas pelo teste-t de Student a 5\% de probabilidade.

Não houve diferença significativa entre os tratamentos ausência ou presença de Si na solução nutritiva para o teor foliar de $\mathrm{Si}$ (valores médios de 0,43 e $0,45 \%$, respectivamente). Houve diferença significativa entre esses tratamentos para o teor de $\mathrm{Si}$ nas raízes (valores médios de 0,25 e $0,5 \%$, respectivamente). Houve um incremento de $50 \%$ no teor de Si nas raízes de plantas supridas com Si em relação à ausência desse elemento na solução nutritiva. As espécies de plantas diferem quanto à capacidade em absorver o Si do solo e translocá-lo, de forma eficiente, para a parte aérea (Ma \& Takahashi, 2002). O arroz, a cana-de-açúcar e outras gramíneas, reconhecidas como acumuladoras de $\mathrm{Si}$, chegam a apresentar até $5 \%$ de Si na matéria seca da parte aérea (Datnoff et al., 2007). Contrariamente, o cafeeiro mostrou ser uma espécie ineficiente em translocar o Si para a parte aérea, porém foi capaz de absorvê-lo da solução nutritiva em teores razoavelmente comparáveis com outras espécies de plantas reconhecidas como não acumuladoras de Si a exemplo do tomateiro (Ma \& Takahashi, 2002). De 
acordo com Botelho et al. (2005), os teores foliares de Si em plantas de cafeeiro supridas com silicato de cálcio e silicato de sódio foram de 0,44 e $0,65 \mathrm{mg} \mathrm{kg}^{-1}$, respectivamente. Esses valores são considerados muito baixos em comparação aos que são relatados na literatura para diversas culturas (Ma \& Takahashi, 2002; Mitani \& Ma, 2005). A eficiência do arroz em absorver ativamente o Si do solo deve-se a presença de proteínas transportadoras do $\mathrm{Si}$ localizadas nas estrias de Caspary da exoderme e da endoderme (Ma et al., 2007). Entretanto, em outras espécies de plantas, a exemplo de $C$. arabica, se desconhece até o momento a presença de genes responsáveis pela produção dessas proteínas carreadoras de Si no sistema radicular.

Nãohouve diferença significativa entre os tratamentos ausência ou presença de Si na solução nutritiva para todos os componentes de resistência avaliados. Os valores para o PI, $\mathrm{PL}_{60}, \mathrm{NTPF}$, área pustular e AACPF foram de 18,7 e 19 dias; 34,8 e 35,8 dias; 83,2 e 85,4; 17,8 e 17,3 $\mathrm{mm}^{2}$ e 2601 e 2169 , respectivamente, para os tratamentos ausência ou presença de Si na solução nutritiva. Para a severidade da ferrugem e EP(Figura 1A-B), não houve diferença significativa entre os tratamentos ausência ou presença de Si na solução nutritiva ao longo das avaliações. Houve diferença significativa entre os tratamentos ausência ou presença de Si na solução nutritiva para notas associadas com o progresso da ferrugem apenas na segunda avaliação (Figura 1C). Nessa avaliação, a maioria das pústulas examinadas nas folhas das plantas supridas com Si apresentavam-se de tamanho médio a grande, com halo clorótico, porém sem esporulação. Ao contrário, nas folhas das plantas não supridas com $\mathrm{Si}$, as pústulas, na sua maioria, eram de tamanho médio a grande, com halo clorótico pronunciado e continham alguns uredósporos. O fornecimento de $\mathrm{Si}$ às plantas seja via solo, solução nutritiva ou foliar, tem resultado num controle satisfatório de várias doenças, tanto em mono quanto em dicotiledôneas (Datnoff et al., 2007). Existem relatos de que no patossistema arroz-Pyricularia grisea e arrozRhizoctonia solani, plantas de arroz de várias cultivares supridas com Si apresentaram reduções significativas em vários componentes de resistência como a taxa de expansão de lesões, freqüência de infecção e área abaixo da curva do progresso da doença (Datnoff et al., 2007). Particularmente em cafeeiro, Martinati et al. (2008) inocularam mudas cultivadas em solo que recebeu a aplicação, a cada dois meses, de doses de Si variando de 0 a $5 \mu \mathrm{M}$ obtidas do silicato de cálcio e magnésio e do silicato de potássio. Embora os autores não tenham encontrado nenhuma relação entre o conteúdo de Si foliar com as doses de Si das duas fontes desse elemento adicionadas no solo, houve uma redução linear no número de lesões nas folhas das plantas em função das doses crescentes de $\mathrm{Si}$ dos dois silicatos. Pozza et al. (2004) relataram que mudas da cultivar Catuaí crescidas em substrato contendo silicato de cálcio tiveram redução de $63,2 \%$ na porcentagem de folhas lesionadas e de $43 \%$ no total de lesões por planta, em relação às plantas que não foram supridas com Si. Observações no microscópio

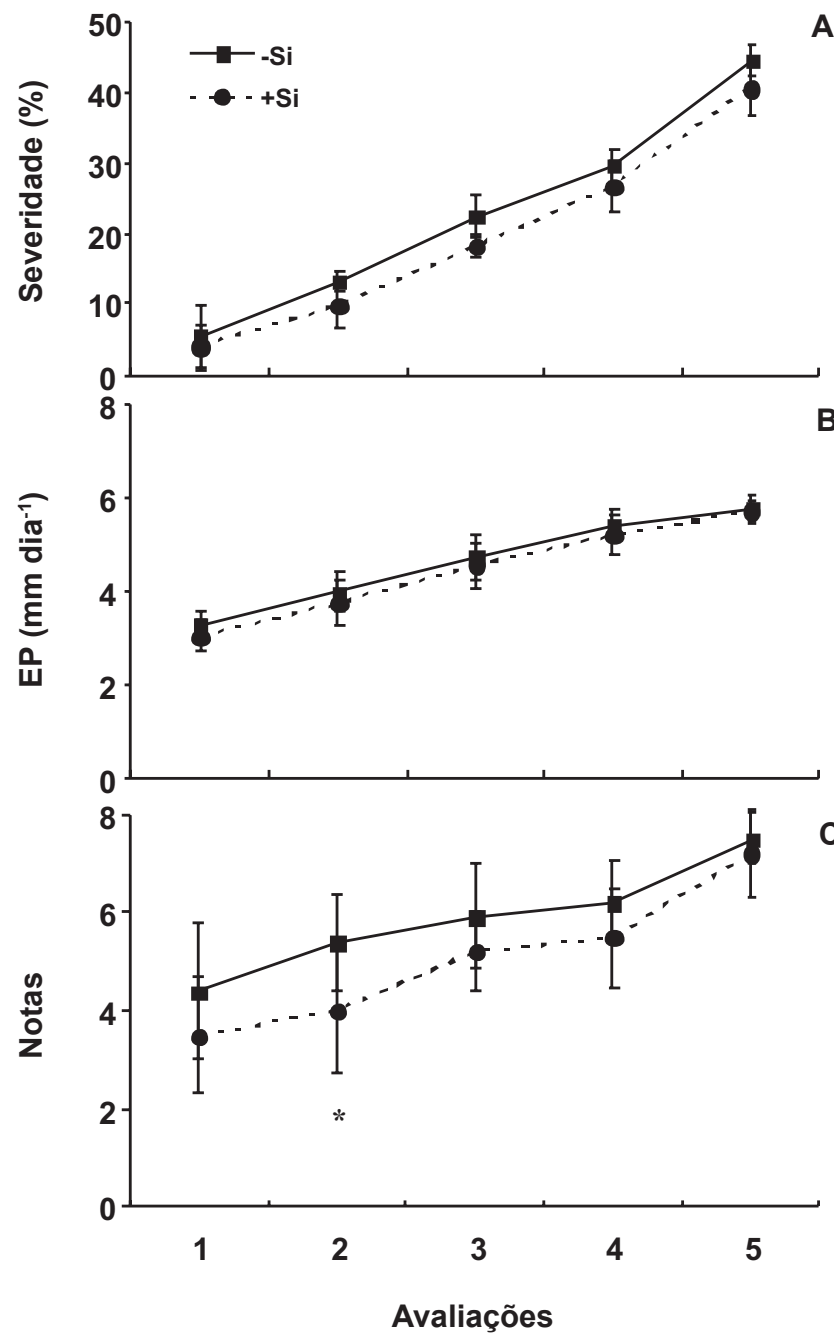

FIGURA 1 - A. Severidade, B. expansão de pústulas (EP) e C. notas para o progresso da ferrugem em folhas de mudas de cafeeiro cultivadas em solução nutritiva sem $(-\mathrm{Si})$ ou com $(+\mathrm{Si})$ a presença de silício $(\mathrm{Si})$. A severidade e o progresso da ferrugem através de notas foram avaliados após a ocorrência do período de incubação $(10,15,20,25$ e 30 dias após inoculação) e a EP após o período latente $(35,37,39,41$ e 43 dias após inoculação), totalizando cinco avaliações para cada um desses componentes. Médias dos tratamentos sem ou com a presença de Si na solução nutritiva com asterisco, em cada avaliação, diferem entre si pelo teste-t de Student ao nível de 5\% de probabilidade. Barras em cada ponto representam o desvio padrão da média.

eletrônico de varredura acoplado a microanálise de raios-X indicaram que em folhas das plantas dessa cultivar supridas com $\mathrm{Si}$, esse elemento foi distribuído uniformemente em toda a superfície abaxial das folhas. Além disso, a camada de cera epicuticular e a cutícula tornaram-se mais espessas na superfície abaxial das folhas de plantas supridas com $\mathrm{Si}$, o que tornou a superfície mais hidrofóbica impedindo, de certa forma, a formação de um filme de água importante para a germinação dos conídios de C. coffeicola. Nas 
folhas das plantas não supridas com Si, a deposição de Si foi raramente observada e não ocorreu nenhuma alteração visual na camada de cera. Botelho et al. (2005) também relataram controle da cercosporiose em mudas de café da cultivar Catuaí IAC99 crescidas em substrato contendo doses crescentes de silicato de cálcio e de silicato de sódio. Nesse estudo, os autores obtiveram os menores valores para a área abaixo da curva de progresso da doença e área abaixo da curva de progresso do número de plantas com cercosporiose, respectivamente, nas doses de 0,84 e $0,52 \mathrm{~g}$ de silicato de sódio por $\mathrm{kg}$ de substrato.

Com relação às variáveis agronômicas avaliadas, diferença significativa entre os tratamentos ausência ou presença de Si na solução nutritiva ocorreu apenas para o comprimento de raízes, sendo que na presença de Si foi onde se obteve os menores valores para essa variável. Em plantas não supridas com Si, a atividade da QUI aumentou até aos 10 DAI, seguido de estabilização até aos 30 DAI (Figura 2). A atividade da QUI apresentou um pico aos 20 DAI em folhas de plantas supridas com $\mathrm{Si}$, seguido de um decréscimo acentuado aos 30 DAI (Figura 2). Diferenças significativas entre os tratamentos ocorreram apenas aos 5, 10, 20 e 30 DAI. Na ausência de $\mathrm{Si}$, houve um pico na atividade da GLU aos 5 DAI, seguido de um decréscimo aos 10 DAI, incremento aos 15 DAI, com redução em atividade até aos 30 DAI (Figura 2). Entretanto, na presença de Si, os valores da atividade da GLU mantiveram-se menores dos 5 até aos 20 DAI, com pico aos 30 DAI (Figura 2). Diferenças significativas entre os tratamentos ocorreram apenas aos 5 e 30 DAI. A atividade da POX decresceu após a inoculação das plantas supridas ou não com Si até aos 10 DAI. Houve um pico na atividade da POX aos 20 DAI nas folhas de plantas não supridas com $\mathrm{Si}$, seguido de decréscimo em atividade aos 30 DAI. Em folhas de plantas supridas com $\mathrm{Si}$, um pico na atividade dessa enzima ocorreu aos 30 DAI. Houve diferença significativa entre os tratamentos em todas as épocas de avaliação, sendo que os maiores valores de atividade foram obtidos em folhas de plantas supridas com $\mathrm{Si}$ aos 5, 10 e 30 DAI. Silva et al. (2008) estudaram a atividade de POX em folhas de mudas de cafeeiro exibindo reação incompatível e compatível à raças de $H$. vastatrix coletadas às $0,18,24,36,42,54$, 72 e 96 horas após inoculação (hai). Os autores observam um pico na atividade dessa enzima às 42 e 96 hai para a reação incompatível e somente às 96 hai para a compatível. Embora se reconheça a importância das enzimas QUI, GLU e POX na resistência do cafeeiro à ferrugem (Guzzo et al., 2004; Silva et al., 2008), no presente estudo constatou-se que a atividade delas aumentou após a infecção dos tecidos foliares por $H$. vastatrix, embora com oscilações durante o período de coletas. Particularmente com relação ao suprimento de $\mathrm{Si}$ às plantas de cafeeiro, não foi observado efeito pronunciado desse elemento em aumentar a atividade dessas enzimas, salvo incrementos em épocas de coletas específicas. Considerando a ineficiência do cafeeiro em translocar o Si das raízes para a parte aérea, esse elemento

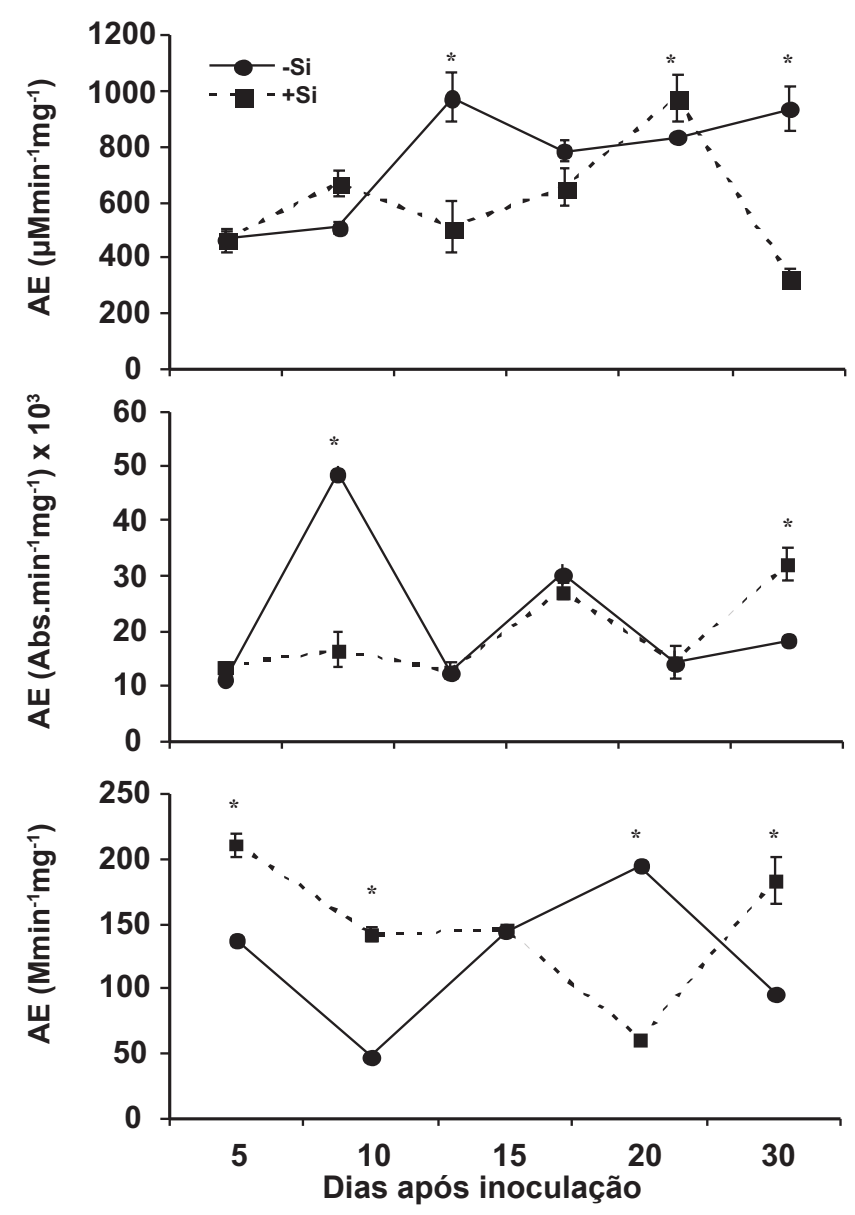

FIGURA 2 - A. Atividade específica (AE) das enzimas quitinases, B. $\beta$-1,3-glucanases e C. peroxidases em folhas de mudas de cafeeiro cultivadas em solução nutritiva sem $(-\mathrm{Si})$ ou com $(+\mathrm{Si})$ a presença de silício $(\mathrm{Si})$ e inoculadas com Hemileia vastatrix. Médias dos tratamentos sem ou com a presença de Si na solução nutritiva, em cada avaliação, com asterisco diferem entre si pelo teste-t de Student ao nível de 5\% de probabilidade. Barras em cada ponto representam o desvio padrão da média.

passa a não ter a capacidade de expressar o seu potencial de, possivelmente, aumentar a atividade dessas enzimas e, dessa forma, reduzir a intensidade da ferrugem. Assim, a redução na intensidade da ferrugem poderia ter ocorrido em função de outros mecanismos de defesa distintos dos avaliados no presente estudo. Rodrigues et al. (2005) relataram para o patossistema arroz- $P$. grisea, que a expressão dos genes codificando para QUI e GLU não foi maximizada pela presença do $\mathrm{Si}$, contudo a transcrição para o gene da POX foi significativamente maior em plantas supridas com Si. Liang et al. (2005) estudou o efeito da aplicação de Si no solo e nas folhas de pepino visando reduzir a severidade do oídio. Os resultados desse estudo mostraram que a aplicação de Si no solo foi mais eficiente em reduzir a severidade do oídio, além de aumentar a atividade das enzimas quitinases, peroxidases e polifenoloxidases. 
Em conclusão, os resultados deste estudo indicaram que o cafeeiro foi ineficiente em translocar o Si das raízes para a parte aérea quando cultivado em solução nutritiva, restringindo-o exclusivamente ao sistema radicular. Assim, a possível potencialização de mecanismos de defesa comumente atribuídas a esse elemento em outros patossistemas passam a não serem fatores determinantes da resistência do cafeeiro à ferrugem. Entretanto, vale ressaltar que esses resultados apontam para a possibilidade de se utilizar o $\mathrm{Si}$ no controle de patógenos radiculares considerando o maior teor desse elemento nas raízes de cafeeiro.

\section{AGRADECIMENTOS}

Ao Conselho Nacional de Desenvolvimento Científico e Tecnológico - CNPq e a Fundação de Amparo à Pesquisa do Estado de Minas Gerais - FAPEMIG pelo apoio financeiro. Ao CNPq pela bolsa de doutorado concedida a V. Carré-Missio e pelas bolsas de produtividade em pesquisa dos professores F.Á. Rodrigues, M.G.A. Oliveira e L. Zambolim. À empresa PQ Silicas Brazil Ltda pelo fornecimento do FertiSil ${ }^{\circledR}$ e ao Prof. Gaspar H. Korndörfer (Universidade Federal de Uberlândia/ICIAG) pela realização das análises de silício no material vegetal.

\section{REFERÊNCIAS BIBLIOGRÁFICAS}

Botelho, DMS, Pozza EA, Pozza AAA, Carvalho JG, Botelho CE, Souza PE (2005) Intensidade da cercosporiose em mudas de cafeeiro em função de fontes e doses de silício. Fitopatologia Brasileira 30:582-588.

Chance B, Maehly AC (1955) Assay of catalases and peroxidases. Methods in Enzymology. vol. 2. New York NY. Academic Press. pp. 764-775.

Clark RB (1975) Characterization of phosphatase of intact morize roots. Journal of Agricultura and Food Chemistry 23:458-460.

Datnoff LE, Rodrigues FA, Seebold KW (2007) Silicon and Plant Nutrition. In: Datnoff LE, Elmer WH, Huber DM (Eds.) Mineral nutrition and plant disease. Saint Paul MN. APS Press. pp. 233-246.

Guzzo SD, Harakava R, Lucon CMM, Tsai SM (2004) Resistência sistêmica adquirida em cafeeiro contra Hemileia vastatrix e indução local e sistêmica de quitinases e $\beta$-1,3-glucanases por acibenzolar-S-metil. Summa Phytopathologica 30:376-381.

Harman GE, Hayes CK, Lorito M, Broadway RM, Pietro A, Peterbauer C, Tronsmo A (1993) Chitinolytic enzymes of Trichoderma harzianum: purification of chitobiosidase and endochitinase. Phytopathology 83:313-318.
Kar M, Mishra D (1976) Catalase, peroxidase, and polyphenoloxidase activities during rice leaf senescence. Plant Physiology 57:315-319.

Kushalappa AC (1978) Uma escala para estimar a intensidade foliar de ferrugem do cafeeiro. Fitopatologia Brasileira 3:119.

Lever M (1972) A new reaction for colorimetric determination of carbohydrates. Analytical Biochemistry 47:273-279.

Liang YC, Sun WC, Si J, Römheld V (2005) Effects of foliar and root applied silicon on the enhancement of induced resistance to powdery mildew in Cucumis sativus. Plant Pathology 54:678685.

Ma FJ, Yamaji N, Mitani N, Tamai K, Konishi S, Fujiwara T, Katsuhara M, Yano M (2007) An efflux transporter of silicon in rice. Nature 448:209-213.

Ma JF, Takahashi E (2002) Soil, Fertilizer, and Plant Silicon Research in Japan. Amsterdam. Elsevier Science.

Marschner H (1995) Mineral Nutrition of Higher Plants. $2^{\text {nd }}$ Edition. London. Academic Press.

Martinati JC, Harakava R, Guzzo SD, Tsai SM (2008) The potential use of a silicon source as a component of an ecological management of coffee plants. Journal of Phytopathology 156:458-463.

Mitani N, Ma JF (2005) Uptake system of silicon in different plant species. Journal of Experimental Botany 56:1255-1261.

Pozza AAA, Alves E, Pozza EA, Carvalho JG, Montanari M, Guimarães PTG, Santos DM (2004) Efeito do silício no controle da cercosporiose em três variedades de cafeeiro. Fitopatologia Brasileira 29:185-188.

Roberts WK, SelitrennikoffCP(1988) Plant and bacterial chitinases differ in antifungal activity. Journal of General Microbiology 134:169-176.

Rodrigues FA, Jurick WM, Datnoff LE, Jones JB, Rollins JA (2005) Silicon influences cytological and molecular events in compatible rice-Magnaporthe grisea interactions. Physiological and Molecular Plant Pathology 66:144-159.

Silva MC, Guerra-Guimarães L, Loureiro A, Nicole MR (2008) Involvement of peroxidases in the coffee resistance to orange rust (Hemileia vastatrix). Physiological and Molecular Plant Pathology 72:29-38.

Silva MD, Oliveira MGA, Lanna AC, Pires CV, Piovesan ND, Jose IC, Batista RB, Barros EG, Moreira MA (2001) Caracterização da via das lipoxigenases em plantas de soja resistentes e susceptíveis a Diaphorte phaseolorum f.sp. meridionalis, agente causal do cancroda-haste. Revista Brasileira de Fisiologia Vegetal 13:316-328.

Yedidia I, Benhamou N, Chet I (1999) Induction of defense responses in cucumber plants (Cucumis sativus L.) by the biocontrol agent Trichoderma harzianum. Applied and Environmental Microbiology 65:1061-1070.

Zambolim L, Vale FXR, Costa H, Pereira AA, Chaves GM (2002) Epidemiologia e controle integrado da ferrugem do cafeeiro. In: Zambolim L (Ed.) O Estado da Arte de Tecnologias de Produção de Café. UFV - Viçosa, MG, Brasil. pp. 369-450. 